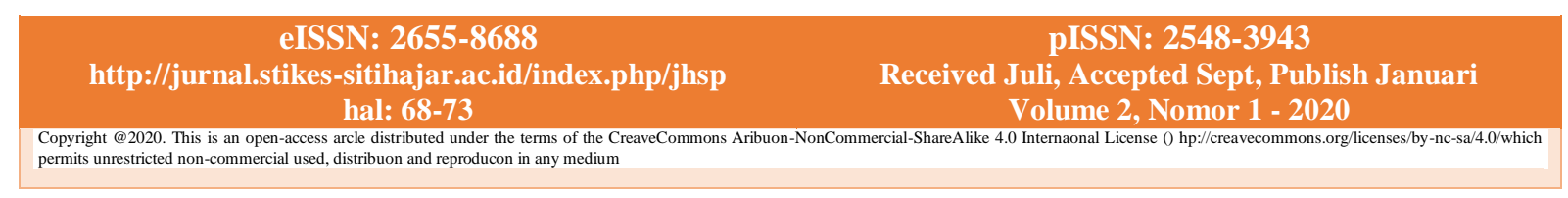

\title{
Kepuasan Pelanggan dan Dampak Terhadap Resiko Penularan HIV/AIDS
}

\section{Customer Satisfaction And Impact On The Risk Of HIV/AIDS Transmission}

\author{
Henna K. Simbolon ${ }^{1 *}$, Herbert Wau ${ }^{2}$ \\ Email: henasimbolon.1@gmail.com
}

\begin{abstract}
ABSTRAK
Wanita pekerja seks (WPS) menjadi salah satu masalah yang harus dihadapi untuk menahan penularan penyakit infeksi menular seksual (IMS) khususnya HIV dan AIDS. Faktor resiko penyakit HIV/AIDS ialah hubungan seks tidak menggunakan kondom, infeksi menular seksual, berbagi jarum suntik, dan tranfusi darah. Tujuan penelitian ini untuk mengetahui penyebab menjadi seorang wanita pekerja seks dan mengidentifikasi pengetahuan wanita pekerja seks tentang resiko HIV/AIDS. Jenis penelitian ini kualitatif dengan teknik wawancara mendalam serta 6 orang informan. Hasil penelitian diperoleh alasan utama mereka menjadi wanita pekerja seks (WPS) adalah masalah ekonomi, keluarga, sakit hati dan suntuk,serta alasan pelanggan tidak mau menggunakan kondom dikarenakan tidak merasa puas dan risih padahal faktor resiko yang ditimbulkan tidak menggunakan kondom bisa menyebabkan IMS. Pengetahuan para wanita pekerja seks cukup bagus. Disarankan kepada instansi kesehatan untuk lebih meningkatkan pendidikan kesehatan dan melakukan pemeriksaan kesehatan.
\end{abstract}

Kata Kunci: Perilaku wanita pekerja seks (WPS), Resiko penyakit HIV/AIDS.

\begin{abstract}
Female sex workers (FSW) is one of the problems that must be faced to curb the transmission of sexually transmitted infections (STIs), especially HIV and AIDS. Risk factors for HIV / AIDS are unprotected sex, sexually transmitted infections, sharing needles and blood transfusions. The purpose of this study was to determine the causes of being a female sex worker and identify the knowledge of female sex workers about the risk of HIV / AIDS. This type of research is qualitative with in-depth interview techniques and 6 informants. The results of the study showed that the main reasons for them to become female sex workers (WPS) were economic problems, family problems, heartache and insults, as well as the reason customers did not want to use condoms because they were not satisfied and uncomfortable even though the risk factors caused by not using condoms could cause STIs. The knowledge of women sex workers is quite good. It is recommended to health agencies to further improve health education and conduct health checks
\end{abstract}

Keywords:The behavior of female sex workers (WPS), risk of HIV/AIDS. 


\section{Pendahuluan}

Wanita pekerja seks (WPS) adalah seseorang yang menjual jasanya dengan melakukan hubungan seksual dengan ganti-ganti pasangan hanya untuk mendapatkan uang dan bersenangsenang tanpa memikirkan resiko dari pekerjaannya. Di Indonesia wanita pekerja seks disebut pelacur karena melakukan pekerjaan yang hina dan kotor (Harnani, 2015).

Prostitusi atau pelacuran adalah gejala sosial ketika wanita menyediakan dirinya untuk perbuatan seksual sebagai mata pencahariannya. (Bonger, 2005).

Dampak akibat dari pekerjaannya menjajakan tubuhnya dengan ganti-ganti pasangan banyak menimbulkan danmenyebarluaskan penyakit kelamin dan kulit, tidak hanya menimbulkan penyakit melainkan menimbulkan kerusakan didalam rumah tangga orang lain dan di lingkungan masyarakat (Kartono, 2011).

Perilaku wanita pekerja seks (WPS) yang beresiko menjadi salah satu masalah yang dihadapi untuk menahan laju perkembangan penularan penyakit IMS, khususnya HIV dan AIDS. Wanita pekerja seks (WPS) pada umumnya mengatakan dengan alasan ekonomi, keluarga, riwayat masa lalu (Shanti R dkk, 2009).

Menurut data World Health Organization (WHO) sebanyak 33,2 juta orang yang hidup dengan HIV yang terdiri dari 30,8 juta orang dewasa, 15.4 juta orang wanita dan 2.1 juta anak dibawah umur 15 tahun. Lebih kurang 6800 infeksi HIV baru dalam sehari pada tahun 2007 yang terdiri dari 5800 dewasa dan 50\% wanita dan $40 \%$ terdiri dari golongan muda yang berumur antara 15-24 tahun. Jumlah penderita lebih kurang 1200 orang anak-anak berumur di bawah 15 tahun dan lebih $96 \%$ dari negara golongan pendapatan rendah dan sederhana.

Indonesia salah satu negara Asia yang mengalami pandemi HIV/AIDS dengan prevalensi yang meningkat tajam dan dari tahun ketahun belum menunjukkan penurunan meskipun upaya penanggulangan telah dilaksanakan oleh masyarakat, Lembaga swadaya masyarakat (LSM). Kasus pertama AIDS pertama di Indonesia dilaporkn secara resmi oleh Departemen Kesehatan pada tahun 1987 seorang warga negara Belanda di Bali (Djoerban Z dkk, 2006).

Dalam sepuluh tahun terakhir peningkatan HIV/AIDS. Pada tahun 2010 jumlah kasus baru untuk HIV(+) yaitu 171 kasus dan AIDS sebanyak 468 kasus. Penambahan kasus baru pada tahun 2011 menyebabkan peningkatan jumlah kasus HIV/AIDS secara keseluruhan menjadi 3.237 kaus. Pada tahun 2012 jumlah kasus HIV/AIDS meningkat tajam menjadi 6.430 kasus dengan rincian 2.189 kasus HIV dan 4.241 kasus AIDS (Laporan Program P2P Dinkes Provsu, 2012).

Salah satu faktor anak perempuan bisa terjun ke dunia prostitusi yaitu karena gaya hidup. Lingkungan para wanita pekerja seks (WPS) bekerja biasanya memang kerap terhubung dengan pergaulan yang kurang menyehatkan seperti merokok, minum-minuman keras bahkan narkoba. Cara hidup mereka yang boros membuat para pekerja seks komersial tersebut bertahan dengan profesi mereka (Suyanto B, 2014).

Penyakit HIV/AIDS sangat terkait dengan perilaku Memberikan motivasi kepada seseorang bisa dengan cara pendidikan kesehatan atau konseling, motivasi bisa juga diperoleh dari keluarga, teman terdekat atau seseorang yang dipercayainya. Motivasi sangat diperlukan untuk perubahan perilaku seseorang tanpa motivasi perubahan perilaku seseorang tidak akan pernah berubah (Hersey dkk, 2011)

Berdasarkan hasil penelitian Idayati (2002), dapat disimpulkan bahwa ada hubungan negatif yang sangat signifikan antara religiusitas dengan perilaku seks bebas di kalangan wanita pekerja seks (WPS), kekerasan rumah tangga, yang sedang pacaran, dimana semakin tinggi religiutas makan perilaku seks bebas semakin rendah dan sebaliknya faktor lain adalah lingkungan. 
Dari hasil penelitian yang dilakukan oleh Munawaroh (2010), dengan menggunakan metode deskriptif kualitatif kepada wanita pekerja seks (WPS) mengungkapkan rendahnya tingkat pendidikan merupakan salah satu penyebab wanita menjadi wanita pekerja seks (WPS).

Hasil penelitian Israwati dkk (2002), perilaku seks bebas pada wanita pekerja seks (WPS), menunjukkan bahwa pengetahuan mereka akan seksualitas sangat terbatas. Pengetahuan tentang kesehatan reproduksi ternyata tidak berpengaruh terhadap wanita pekerja seks (WPS) dalam melakukan pekerjaan tersebut

Berdasarkan data Profil Dinas Kesehatan Kabupaten Samosir 2014. Peningkatan HIV/AIDS pada Tahun 2014 jumlah kasus baru HIV (+) yaitu 1 kasus ditemukan juga kasus AIDS sebanyak 2 kasus dan ditemukan angka kematian akibat AIDS sebanyak 1 kasus. Berdasarkan karakteristik penderita diketahui penderita terbanyak adalah pria sekitar $75 \%$ dan wanita $25 \%$.

Survey awal yang telah saya lakukan kepada wanita pekerja seks (WPS) pada Desember 2018 terhadap 1 orang mucikari mengatakan bahwa anggota pekerjanya kriteria umur rata-rata dari 25-49 tahun. Wanita pekerja seks ada yang tau dan ada yang tidak tau tentang resiko penyakit HIV/AIDS yang penting mereka melakukan pekerjaanya dan tetap mendapatkan hidup yang sejahtera.

Sehingga peneliti ingin melanjutkan penelitian perilaku wanita pekerja seks komersial (WPS) dan resiko penyakit HIV/AIDS di Desa Pintubatu Kecamatan Pangururan Kabupaten Samosir Tahun 2019.

\section{Metode Penelitian}

Penelitian ini menggunakan metode penelitian kualitatif dengan wawancara mendalam. Penelitian ini dilaksanakan di Kafe Ria Pintubatu Kecamatan Pangururan Kabupaten Samosir. Waktu penelitian ini dari bulan Desember - Juni 2019. Kriteria informan dalam melakukan penelitian ini berdasarkan ketersediaan informan untuk diwawancarai, dapat dipercaya dan menjadi sumber data yang baik. Populasi dalam penelitian ini adalah informan utama sebanyak 4 orang, informan pendukung 1 orang mucikari dan 1 orang petugas kesehatan.

\section{Hasil dan Pembahasan}

Lokasi penelitian ini berada di Desa Pintubatu, Kecamatan Pangururan, Kabupaten Samosir, Sumatera Utara.

Kemudian penelitian dilakukan dengan cara wawancara mendalam menggunakan alat perekam suara dan setelah wawancara selesai peneliti memberikan pendidikan kesehatan kepada para wanita pekerja seks tentang masa inkubasi penyakit HIV/AIDS. Dan peneliti membuat hasil wawancara pernyataan informan untuk dianalisa.

\section{Perilaku Wanita Pekerja Seks dan Resiko penyakit HIV/AIDS}

Pernyataan informan petugas kesehatan tentang perilaku wanita pekerja seks dan resiko HIV/AIDS pada wanita pekerja seks (WPS), tingkat pengetahuannya cukup bagus. Dapat disimpulkan bahwa petugas kesehatan telah memberikan pendidikan kesehatan dengan baik.

Sedangkan pernyataan informan pendukung yaitu mucikari tentang resiko HIV/AIDS cukup baik, mampu menjelaskan tentang pencegahan resiko penyakit tersebut dan sangat menerima jika petugas kesehatan datang melakukan penyuluhan kesehatan.

Berdasarkan hasil penelitian menunjukkan bahwa wanita pekerja seks pada dasarnya cukup aktif mencari informasi tentang penyakit menular HIV/AIDS melalui teman-temannya yang sudah lama bekerja dan petugas kesehatan. Sehingga mereka menganjurkan pelanggan agar menggunakan kondom pada saat berhubungan. 


\section{Perilaku Wanita Pekerja Seks dan Resiko penyakit HIV/AIDS}

Pernyataan dari 4 orang informan utama untuk pengetahuan tentang perilaku dalam mengatasi resiko penyakit HIV/AIDS adalah baik. Dapat disimpulkan bahwa informan mengerti resiko yang akan terjadi dari profesi dari yang sedang dijalaninya.

\section{Pembahasan}

\section{Keluarga}

Dari hasil wawancara mendalam kepada 5 orang informan diperoleh informasi salah satu alasan utama mereka terjun menjadi wanita pekerja seks (WPS) adalah masalah keluarga. Mereka merasa sakit hati karena ditinggal nikah oleh suaminya dan keluarga suami tidak peduli. "awalnya aku cerai dengan suami kuh ditinggal kawin (IZ)"

Dan hal senada IN juga mengatakan, Seperti hal berikut : "faktor tekanan hidup kayak aku awalnya suntuk gak taumau kemana ngadu orangtua gak ada keluarga laki-laki gak pernah peduli dan lepas tanggung jawab anak-anak semua sama kuh itu sebabnya aku terjun ke dunia seperti ini,anak ku 3 SMA 1, SMP 1, kelas 5 SD. Intinya aku yang hidup inimemperjuangkan anak lainnya itu gak ada. Saudara perempuan aku gak punya, gak mungkin anak ku perempuan ku sia-siakan kan perlu tempat tinggal, sekolah, makan segala macam (IN)"

Berdasarkan penelitian yang Munawaroh (2010), faktor keluarga merupakan alasan terjun menjadi seorang wanita pekerja seks (WPS). Latar belakang keluarga yang tidak utuh (broken home), ditinggal nikah suami dan juga karena suami tidak bekerja dan tidak ada penghasilan untuk kebutuhan hidup sehari-hari.

\section{Ekonomi}

Dari hasil wawancara terhadap 5 orang informan, mereka mengatakan terjun menjadi seorang wanita pekerja seks berawal dari kehidupan yang serba kekurangan . Masalah ekonomi yang merupakan salah satu alasan mereka terjun menjadi seorang wanita pekerja seks (WPS). Seperti kutipan berikut.

"karena faktor ekonomi yah, karena kebutuhan meningkat anak semakin besar gitu ajalah. Cemana dibilang yah mungkin karena baru janda yang ada dikerjakan itu istilahnya tidak cukup untuk anak-anak untuk kebutuhan sehari-harilah (IN)".

IM juga mengungkapkan alasan utamanya menjadi seorang wanita pekerja seks (WPS) yang baru satu hari bekerja adalah :

"karena kebutuhan ekonomi anak-anak sekolah, aku juga punya baby umur setahun jadi kebutuhan itu gk netap suami ku gk bekerja sudah berumur dan udah sakit-sakitan (IM)"

Menurut (Roem, 2014) tidak dapatdipungkiri bahwa uang memiliki pengaruh penting dalam menjalani kehidupan manusia termasuk untuk kebutuhan sehari-hari. Masalah ekonomi adalah alasan utama menjadi seorang wanita pekerja seks (WPS) yang dapat menghasilkan uang.

\section{Pengetahuan}

Hasil wawancara mendalam dari 5 orang informan didapatkan informasi bahwa pengetahuan informan mengenai resiko penyakit HIV/AIDS sudah cukup baik dalam penerimaan penyuluhan kesehatan dan pencegahan penyakit yang selalu periksa ke petugas kesehatan. Seperi halnya yang diungkapkan :

"Sekali sebulan kadang sekali sebulan, kalau kami orang ini berobat sekali 2 minggu dan antibiotik setiap hari dan kalau untuk kesehatan orang ini selalu lah. Kalau 
ditempat ku ini selalunyakuperingati masalah kesehatan. Kami gak pernah menolak kalau penyuluhan kesehatan datang kami pengen taukalau memang kita sakit biardiobati.Dokter sendiri disini dan selalu ditelusuri kalau kami pun tau ada kami suruhberobat kami pulangkan. Pernah ada yang kena tapi pendatang, itupun sudah kami pulangkan.Kondom dibagi disini dan di anjurkan ke pelanggan tapi aneh tanggapannya karena katanya pake kondom ini gak seru gak kena kulit padahal kita kan menjaga (IZ)"

Menurut Notoatmodjo (2010), pengetahuan merupakan hasil dari tahu seseorang dan terjadi setelah orang tersebut melakukan penginderaan terhadap suatu objek tertentu. Pengetahuan atau kognitif merupakan domain yang sanagat penting dalam membentuk tindakan seseorang (Over Behavior). Perilaku yang didasari oleh pengetahuan akan lebih baik daripada perilaku yang tidak didasari oleh pengetahuan, biasanya pengetahuan seseorang diperoleh dari pengalaman yang berasal dari berbagai sumber.

\section{Sikap}

Hasil wawancara kepada informan diperoleh informasi bahwa mereka awal terjun menjadi wanita pekerja seks (WPS), merasa sedih, menangis, terpaksa dan awalnya tidak langsung bekerja. Namun lama kelamaan jadi terbiasa.

Seperti halnya yang dikatakan :

"sedih loh disini siapalah gak sedih kita harus menerima orang yang gak kita suka, menghadapiorang mabuk. Tapi kami harus punya tabungan untuk anak kalau daripelanggan semua gak sama kalau ada yang baik Rp. 500.000 (IP)”

Dan informan IN mengatakan seperti kutipan berikut:

" dulu aku langsung disuruh melayani trus akutamparlahkan katanya kau janganmunafiklah digtuin aku gakmunafik bg, aku gak tau, di tumpahi lah sama ku minuman jam 2 pagi sampe aku nangis. Betul saya gak taumeladeni laki-laki singkat cerita di letakin duit satu (IZ)"

gepok kurasa kalau ku ambil itu udah lama aku tobat

Hal ini sesuai dengan penelitian Arifianti (2008), dimana sikap negatif terhadap kegagalan rumah tangga menjadikan mereka berprofesi wanita pekerja seks (WPS). Awalnya mereka sedih, menangis. Namun tidak ada pernah berniat untuk bunuh diri dan dari pekerjaannya sekarang mereka menikmati hasilnya walaupun mereka tau resiko dari pekerjaan yang sedang dijalaninya sekarang.

\section{Perilaku}

Hasil wawancara kepada informan diperoleh bahwa pengaruh teman salah satu alasan mereka terjun ke profesi wanita pekerja seks. Bahkan yang semula tidak tahu apa-apa tentang prostitusi akhirnya ikut terjun menjadi wanita pekerja seks (WPS) hanya karena ajakan dari orang sekitarnya.

Seperti yang dikatakan IL:

"aku dulu udah sempat berhenti gak kerja gini lagi kemarin kan udah sempat anartantar pesanan orang ini, bisnis sempatjual-jual pakaian namanya kek mana yah udah terbiasa dan gak bisa terpisah dari kawan-kawan humoris orang ini, suntuk juga dirumah (IL)"

Informan IN juga mengatakan:

"suntuk, stres, depresi gak tau mau kemana ada juga sih teman aku kek gitu dikampung ikut dia. Ngadu amakawan solusinya yah gitulah ayo ayo yah jadi setelah dijalanin 
sedih juga sih. pertama kali aja aku nangis tutup muka bantal tapi lama-lama jadi terbiasa (IN).

Perilaku atau aktivitas yang ada pada individu atau organisme itu tidak timbul dengan sendirinya, tetapi sebagai akibat dari stimulus yang diterima oleh organisme yang bersangkutan baik stimulus skternal maupun stimulus internal.

Menurut (Thoha M, 2010:33), perilaku merupaka fungsi dari interaksi antara individu dan lingkungan sekitar.

\section{Kesimpulan}

1. Setiap manusia memiliki masalah yang berbeda-beda, cara berpikir dan prosesnya saja yang berbeda begitu halnya dengan wanita pekerja seks (WPS) memiliki faktor yang menyebabkan mereka melakukan pekerjaan tersebut, diantaranya adalah faktor ekonomi dimana pada awalnya mereka harus membiayai anak-anak serta keluarganya. Selain faktor ekonomi masalah keluarga juga sangat berpengaruh untuk mereka terjun menjadi seorang wanita pekerja seks (WPS) adanya perceraian, suntuk, keluarga yang lain tidak peduli, sementara mereka harus memenuhi kebutuhan anak-anak mereka.

2. Tingkat pengetahuan para wanita pekerja seks (WPS) cukup bagus, karena mereka mengetahui dampak dari penyakit dari pekerjaannya dan mereka mempunyai dokter untuk selalu periksa kesehatan.

\section{Saran}

1. Profesi menjadi wanita pekerja seks (WPS) adalah pekerjaan yang sangat beresiko untuk kesehatan dan juga masalah besar untuk diri sendiri serta keluarga jika mengetahui. Akan tetapi lebih baik mencari pekerjaan lain atau membuka usaha kecilkecilanmungkinpenghasilannya lebih sedikitnamun hal itu akan lebih baik daripada mendapatkan uang dari pekerjaan yang sangat beresiko untuk kesehatan.

2. Untuk petugas kesehatan agar selalu mendatangi lokasi dan memberikan pendidikan kesehatan agar wanita pekerja seks (WPS) lebih memikirkan resiko dari pekerjaan yang sedang dijalaninya tersebut.

\section{Referensi}

Febri Destrianti., Yessi Harnani, 2018. Studi Kualitatif Pekerja Seks Komersial Di Daerah Jondul Kota Pekanbaru Tahun 2016.

Liawati, 2018. Faktor Yang Berpengaruh Terhadap Perilaku Pencegahan HIV/AIDS Pada Pekerja Seks Komersial (PSK) Di Kota Bandung Tahun 2017.

Rachmawati, Putri. 2016. Fenomena Kehidupan "Ayam Kampus” (Studi Kasus Mahasiswi Di Surabaya).

Siti, Munawaroh. 2010. Pekerja Seks Komersial (PSK) Di Wilayah Prambanan, Kabupaten Klaten, Jawa Tengah.

Pangaribuan, Maria, Santa. Wiwi, Mardiah. 2017 Gambaran Tingkat Pengetahuan Wanita Pekerja Seks Komersial Tentang Infeksi Menular.

Permatasari, Santika. dkk. Fenomena Pekerja Seks (PSK) di Kawasan Stasiun Kereta Api Kutuarjo, Kabupaten Purworejo, Provinsi Jawa Tengah.

Sulaiman, Anggriani. Hubungan Mutu Pelayanan terhadap kepuasan Pasien di Poli Fisioterapi RSU Siti Hajar. Jurnal Endurance: Kajian Ilmiah Problema Kesehatan 4(2), 252-256, 2019. 